\title{
Outcomes of the bidirectional Glenn procedure in patients less than 3 months of age
}

\author{
Orlando Petrucci, MD, PhD, ${ }^{\mathrm{a}}$ Philip R. Khoury, MS, ${ }^{\mathrm{b}}$ Peter B. Manning, MD, ${ }^{\mathrm{c}}$ and \\ Pirooz Eghtesady, $\mathrm{MD}, \mathrm{PhD}^{\mathrm{c}}$
}

\begin{abstract}
Objective: The bidirectional Glenn procedure is a well-established procedure performed as part of the single-ventricle palliation pathway. Numerous studies have highlighted the potential benefits of an "early" BDG procedure. The ideal age to perform the BDG procedure, however, remains uncertain. We report our experience with the BDG procedure in patients younger than 3 months.
\end{abstract}

\begin{abstract}
Methods: One hundred sixty-nine consecutive patients from 1998 to 2007 undergoing the BDG procedure were divided into 2 groups: younger than 3 months $(n=20)$ and older than 3 months. The groups were compared for 26 variables. All data were analyzed with Kaplan-Meier survival analysis and the Cox proportional hazard regression test to assess the probability of survival after the BDG procedure in both groups. A stepwise regression analysis was performed for identification of independent factors for postoperative oxygen saturation at hospital discharge.
\end{abstract}

Results: The groups were comparable, with an equal distribution of patients with right-sided or left-sided singleventricle anatomy. Although intensive care unit length of stay, ventilation time, and hospital length of stay were longer in the younger group, room air oxygen saturations at discharge, both early and late mortality, and time to the Fontan procedure were similar between groups. The independent variables found for death after the BDG procedure were preoperative mean pulmonary artery pressure, atrioventricular valve regurgitation, and postoperative oxygen saturations at hospital discharge. Survival in patients with hypoplastic left heart syndrome was comparable between groups after 5 years of follow-up.

Conclusion: The BDG procedure is feasible and safe in patients as young as 2 months of age, with early and late mortality equivalent to that seen in older patients. (J Thorac Cardiovasc Surg 2010;139:562-8)

The bidirectional cavopulmonary shunt (bidirectional Glenn procedure $[\mathrm{BDG}])$ is a well-established procedure performed as part of the single-ventricle pathway that culminates in the Fontan procedure. ${ }^{1}$ There have been numerous studies looking at the timing of the BDG procedure, with many highlighting the potential benefits of performing an " "early" BDG procedure. These include removing a volume load from the single ventricle that can benefit atrioventricu$\operatorname{lar}(\mathrm{AV})$ valve insufficiency and perhaps improve long-term diastolic function, decreasing the effective cardiac output required from the single ventricle, avoiding potential pulmonary tree distortions seen with systemic to pulmonary shunts, and perhaps preventing the development of pulmonary vascular obstructive disease from the same. ${ }^{2}$ Despite increased reports in the literature documenting the early BDG

From the Discipline of Cardiac Surgery, ${ }^{\text {a }}$ Faculty of Medical Science, State University of Campinas, UNICAMP, Campinas, Brazil; and the Divisions of Cardiology ${ }^{\mathrm{b}}$ and Cardiothoracic Surgery, ${ }^{\mathrm{c}}$ Cincinnati Children's Hospital Medical Center, University of Cincinnati, Cincinnati, Ohio.

Disclosures: None.

Received for publication April 21, 2009; revisions received July 2, 2009; accepted for publication Aug 10, 2009; available ahead of print Nov 12, 2009.

Address for reprints: Pirooz Eghtesady, MD, PhD, Division of Cardiothoracic Surgery, Cincinnati Children's Medical Center, 3333 Burnet Ave, Cincinnati, OH 45229-3032 (E-mail: pirooz.eghtesady@cchmc.org).

$0022-5223 / \$ 36.00$

Copyright (c) 2010 by The American Association for Thoracic Surgery doi:10.1016/j.jtcvs.2009.08.025 procedure, ${ }^{3,4}$ there is continued controversy regarding the timing, with some arguing little benefit in waiting beyond 4 months ${ }^{4}$ and others cautioning against performing the procedure in those younger than 3 months. ${ }^{5}$ These cautions stem from concern with possibly increased mortality and morbidity with an early BDG procedure, the possibility that the pulmonary arteries will not be as well developed with passive flow, and the potential adverse effects on cerebral circulation or long-term candidacy for Fontan completion.

Although some prior reports, mainly from the 1990s, document poor outcomes, ${ }^{6,7}$ more recently, others have shown good outcomes in younger patients after the BDG procedure. ${ }^{4,8,9}$ Nevertheless, the ideal age and age limits to perform the BDG procedure remain uncertain. The purpose of this report is to show our experience with the BDG procedure in patients younger than 3 months and to identify which predictive variables either impede or enhance progress to the Fontan procedure.

\section{MATERIALS AND METHODS Data Collection}

After institutional review board approval, a retrospective review of data was carried out in a cohort of patients who had undergone the BDG procedure from 1998 to 2007 at our institution. Patient files were analyzed for demographic, echocardiographic, and catheterization data. Patients who had 


\section{Abbreviations and Acronyms \\ $\mathrm{AV}=$ atrioventricular \\ $\mathrm{BDG}=$ bidirectional Glenn procedure \\ BT = Blalock-Taussig \\ HLHS = hypoplastic left heart syndrome \\ ICU = intensive care unit}

been lost to follow-up, patients with incomplete data, or both were excluded from the study.

Patients undergoing the BDG procedure were divided into 2 groups based on age at the time of the operation: patients less than 3 months of age (younger group) were compared with patients who were older than 3 months (older group). The older group was referred for the BDG procedure solely at the discretion of the referring cardiologists and typically for worsening cyanosis. The younger group, in contrast, could be categorized into one of 2 groups. One was a nonpalliated group who presented because of cyanosis (with or without heart failure), and the initial step of (usually) Blalock-Taussig (BT) shunt was skipped in favor of an early BDG procedure. The other category included patients with hypoplastic left heart syndrome (HLHS) after first-stage palliation who were pushed toward an early BDG procedure in the hopes of unloading their ventricles, with resultant improvement in their clinical status.

Preoperative records and follow-up data were reviewed. Detailed clinical diagnoses with comorbidities, duration of hospital stay, duration of intensive care unit (ICU) stay, and time from admission to surgical intervention were recorded. The duration of ventilation time and preoperative and postoperative room air oxygen saturations at hospital discharge were also noted.

The preoperative echocardiographic information, such as right and left pulmonary branch sizes and AV valve regurgitation, were recorded. AV valve regurgitation was graded as severe, moderate, mild, or absent based on pulse wave tracing and color Doppler mapping. Data from cardiac catheterizations performed before the BDG procedure were reviewed. Systemic oxygen saturations on room air, indexed pulmonary and systemic cardiac output ratio, ventricular end-diastolic pressure, mean pulmonary artery pressure, and indexed pulmonary vascular resistance were noted from catheterization records. Because of difficulties attributable to vascular access or clinically based decisions, not all patients were catheterized nor were catheterization data variables available for all patients $(n=17)$. The time between catheterization and the BDG procedure was variable but generally no longer than 3 weeks.

Surgical details noted included cardiopulmonary bypass time; procedures done before the BDG procedure, such as the Norwood procedure, pulmonary artery banding, or a prior BT shunt; and simultaneous procedures done at the time of the BDG procedure, such as pulmonary artery band tightening and atrial septectomy. In addition, a note was made of the presence or absence of antegrade pulmonary blood flow before and after the BDG procedure. We defined antegrade flow as any flow through the native main pulmonary artery and pulmonary valve only; patients who received a right ventricle to pulmonary artery conduit (eg, Sano modification) as part of their initial palliation were not included under this definition. For all patients, the anastomosis was constructed in an end-to-side fashion after division of the superior vena cava and oversewing of the cardiac end of the vessel. In most patients the BDG procedure was performed with cardiopulmonary bypass support, whereas in some the procedure was carried out off-pump, typically if there was antegrade blood flow from the ventricle to the main pulmonary artery. Crossclamp time reflects the ischemic time that was incurred in those patients requiring additional procedures at the time of the $\mathrm{BDG}$ procedure (eg, creation of an atrial septal defect). A bilateral cavopulmonary anastomosis was constructed in the presence of bilateral superior vena cavae. Surgical techniques were not different between the younger and older groups. For anticoagulation, heparin was used in the immediate postoperative period and then replaced with aspiring after removal of intracardiac lines. It was recorded on late follow-up whether Fontan procedure was completed and, if so, the time interval to the Fontan completion. Early surgical mortality was defined as mortality before hospital discharge or at 30 days, whichever was latest, according to the Society of Thoracic Surgeons guidelines. Longterm mortality was any mortality beyond the early period.

\section{Statistical Analysis}

All data were expressed as medians, means \pm standard deviations, or both. Twenty-seven variables (collected from both groups before, at the time of, and after the BDG procedure) were analyzed and compared between the 2 groups (Table 1). For time variables, the numbers of postoperative days were noted (eg, from postoperative day 0 to 1 is considered 1 day). Comparisons between the 2 groups was made by using the $\chi^{2}$ test for categorical variables, variance-stabilizing transformations being performed as appropriate. Mean values for variables (collected from both groups before, at the time of, or after the BDG procedure) were compared between the 2 groups by using the $t$ test or Wilcoxon rank sum test as appropriate. Kaplan-Meier survival and stepwise Cox proportional hazards regressions analyses were performed to assess survival after the BDG procedure in both groups. The Cox model was adjusted for room air postoperative oxygen saturations at discharge, preoperative mean pulmonary artery pressure, age at the time of the BDG procedure, the presence of antegrade pulmonary blood flow before the BDG procedure, and preoperative calculated pulmonary vascular resistance.

A stepwise regression analysis was performed to identify independent factors for postoperative oxygen saturation at hospital discharge. Independent variables were included in the model if the $P$ value was less than .05 .

\section{RESULTS}

During the study period, 183 patients underwent the BDG procedure. Fourteen patients (all $>3$ months of age at the time of the BDG procedure) were excluded because of missing data or because of loss to follow-up. There were 20 patients younger than 3 months of age (younger group) and 149 patients older than 3 months of age (older group). Demographics, age at the time of the BDG procedure, associated procedures, length of hospital stay, duration of mechanical ventilation, length of ICU stay, and primary diagnoses are summarized in Table 2. At the time of the BDG procedure, the youngest patient was 55 days old, and the oldest patient was 660 days old.

The younger group showed fewer prior operations than the older group $(50.00 \%$ vs $85.23 \%, P=.0041)$. In the younger group the prior operations were as follows: 1 patient underwent pulmonary artery banding with simultaneous coarctation repair, 2 patients underwent the BT shunt procedure, and 7 patients underwent first-stage HLHS palliation, one of whom never left the hospital until the BDG procedure.

All preoperative hemodynamic data are summarized in Table 3. The echocardiographic data are also summarized in Table 3. Branch pulmonary arteries were of similar size between groups, as well as the degree of AV valve regurgitation for every classification: absent, mild, and moderate.

The late outcome after the BDG procedure was similar in both groups (Table 4). There were no patients in the younger group requiring heart transplantation, whereas in the older group there were 4 patients requiring heart transplantation, but this difference was not statistically significant $(P=.97)$. 
TABLE 1. Variables analyzed

\begin{tabular}{ccc}
\hline $\begin{array}{c}\text { Variables before } \\
\text { BDG procedure }\end{array}$ & $\begin{array}{c}\text { Variables at time of } \\
\text { BDG procedure }\end{array}$ & $\begin{array}{c}\text { Variables after } \\
\text { BDG procedure }\end{array}$ \\
\hline $\begin{array}{c}\text { Right pulmonary } \\
\text { artery size }\end{array}$ & Body surface area & ICU length stay \\
$\begin{array}{c}\text { Left pulmonary artery } \\
\text { size }\end{array}$ & $\begin{array}{c}\text { Concomitant } \\
\text { procedures at time } \\
\text { of BDG procedure }\end{array}$ & $\begin{array}{c}\text { Mechanical } \\
\text { ventilatory support } \\
\text { time }\end{array}$ \\
Atrioventricular valve & $\begin{array}{c}\text { Presence of } \\
\text { comorbidities }\end{array}$ & Time to follow-up \\
regurgitation & Cardiopulmonary & Time to Fontan \\
Oxygen saturation & bypass time & completion \\
Prior surgical & Crossclamp time & Oxygen saturation at \\
procedure(s) & & hospital discharge \\
End-diastolic & & Duration of chest tube \\
ventricular pressure & & drainage \\
Mean pulmonary & & Presence of antegrade \\
pressure & & flow \\
Pulmonary vascular & & Surgical mortality \\
resistance & & \\
Pulmonary/systemic & & \\
cardiac output ratio & & \\
Admittance hospital & & \\
time before BDG & & \\
procedure & & \\
Presence of left & & \\
superior vena cava & & \\
\hline$B D G$, Bidirectional Glenn; $I C U$, intensive care unit. &
\end{tabular}

The postoperative oxygen saturations at discharge (all on room air) were positively associated with previous antegrade flow $(P=.0021)$ and negatively associated with preopera- tive end-diastolic ventricular pressure $(P=.0357)$. Age at the time of the BDG procedure was not associated with worse postoperative oxygen saturations at discharge.

The effect of several risk factors on survival of the entire cohort was assessed with stepwise Cox regression modeling. The hazard ratio for preoperative pulmonary artery pressure was 1.27 (95\% confidence interval, $1.10-1.48 ; P=.0014)$ for each $1 \mathrm{~mm} \mathrm{Hg}$ increment increase, and for postoperative oxygen saturations at hospital discharge, it was $0.81(95 \%$ confidence interval, $0.71-0.94 ; P=.0039)$ for each $1 \%$ of oxygen saturation increment increase. Age at the time of the BDG procedure was not an independent variable for death and did not enter into the regression model. The AV valve regurgitation before the BDG procedure was associated with survival based on univariate analysis.

The evaluation of 2 survival curves showed a survival probability of $94.7 \% \pm 5.12 \%$ in the younger group and $95.7 \% \pm 1.73 \%$ in the older group, with no statistical difference $(P=.82$; Figure $1, A)$.

In the HLHS subgroup late survival in both groups was comparable $(80.0 \% \pm 17.9 \%$ vs $87.4 \% \pm 6.50 \%$, $P=.31$ ), with 1 death in the younger group and 4 in the older group (Figure 1, $B$ ). In the same HLHS subgrouping, postoperative oxygen saturations at discharge were slightly lower in the younger group when compared with those in the older group but with no statistical significance $(77.00 \% \pm 3.46 \%$ vs $81.00 \% \pm 4.86 \%, P=.08)$.

Analyzing all patients (HLHS and non-HLHS diagnosis), the postoperative oxygen saturations at hospital discharge for patients with HLHS were lower when compared with

TABLE 2. Demographics, hospital data summary, and primary diagnoses

\begin{tabular}{|c|c|c|c|}
\hline & $\begin{array}{c}\text { Older group } \\
(n=149)\end{array}$ & $\begin{array}{l}\text { Younger group } \\
\quad(\mathbf{n}=\mathbf{2 0}) \\
\end{array}$ & $P$ value \\
\hline Age at $\mathrm{BDG}$ procedure $(\mathrm{d})$ & $191.4 \pm 7.19$ & $83.15 \pm 3.21$ & $<.0001$ \\
\hline Weight (kg) & $6.13 \pm 0.11$ & $4.83 \pm 0.19$ & $<.0001$ \\
\hline $\operatorname{BSA}\left(\mathrm{m}^{2}\right)$ & $0.32 \pm 0.01$ & $0.27 \pm 0.01$ & $<.0001$ \\
\hline Follow-up (y) & $4.47 \pm 3.23$ & $3.31 \pm 2.75$ & .1625 \\
\hline Time to Fontan procedure (mo) & $39.63 \pm 1.32$ & $39.23 \pm 4.72$ & .9249 \\
\hline Time from hospital admittance to BDG procedure (d) & $1.00 \pm 26.67$ & $3.00 \pm 23.05$ & .0143 \\
\hline Duration of chest tube drainage (d) & $2.1 \pm 1.1(2.0)^{*}$ & $2.8 \pm 2.28(2.0)^{*}$ & .5742 \\
\hline Hospital length of stay (d) & $11.88 \pm 2.51(6.0)^{*}$ & $24.55 \pm 6.74(10.5)^{*}$ & $<.0001$ \\
\hline Mechanical ventilation duration (d) & $3.81 \pm 23.10(1.0)^{*}$ & $8.50 \pm 22.78(2.0) *$ & .0198 \\
\hline ICU length of stay (d) & $7.43 \pm 28.20(3.0)^{*}$ & $13.30 \pm 25.14(4.0)^{*}$ & .0048 \\
\hline Operative mortality & $2(1.34 \%)$ & $1(5.0 \%)$ & .7823 \\
\hline Prior operations & $127(85.23 \%)$ & $10(50.00 \%)$ & .0041 \\
\hline Simultaneous procedures & $21(12.42 \%)$ & $3(15.00 \%)$ & .7365 \\
\hline Crossclamp time & $27.82 \pm 17.92$ & $22.00 \pm 19.67$ & .6408 \\
\hline Pump time (min) & $98.49 \pm 40.40$ & $106.92 \pm 47.33$ & .5459 \\
\hline BDG procedure performed off bypass & $29(19.46 \%)$ & $7(35.00 \%)$ & .1739 \\
\hline HLHS & $51(34.2 \%)$ & $5(25.0 \%)$ & .6420 \\
\hline PA-IVS & $16(10.7 \%)$ & $2(10.0 \%)$ & .8045 \\
\hline Tricuspid atresia & $25(16.8 \%)$ & $3(15.0 \%)$ & .4736 \\
\hline Single ventricle & $57(38.3 \%)$ & $10(50.0 \%)$ & .9325 \\
\hline
\end{tabular}

$B D G$, Bidirectional Glenn; $B S A$, body surface area; $I C U$, intensive care unit; $H L H S$, hypoplastic left heart syndrome; $P A-I V S$, pulmonary atresia with intact ventricular septum. *Median values. 
TABLE 3. Perioperative hemodynamic status and echocardiographic data

\begin{tabular}{|c|c|c|c|}
\hline & $\begin{array}{c}\text { Older group } \\
(\mathrm{n}=149)\end{array}$ & $\begin{array}{c}\text { Younger group } \\
(\mathbf{n}=\mathbf{2 0})\end{array}$ & $P$ value \\
\hline Qp:Qs flow ratio & $1.3 \pm 0.1$ & $1.2 \pm 0.3$ & .45 \\
\hline End-diastolic ventricular pressure $(\mathrm{mm} \mathrm{Hg})$ & $6.8 \pm 0.2$ & $7.1 \pm 0.64$ & .68 \\
\hline Pulmonary mean pressure $(\mathrm{mm} \mathrm{Hg})$ & $13.6 \pm 0.4$ & $13.2 \pm 1.5$ & .73 \\
\hline Pulmonary vascular resistance $\left(\mathrm{WU} / \mathrm{m}^{2}\right)$ & $2.7 \pm 0.1$ & $1.9 \pm 0.2$ & .4937 \\
\hline Preoperative oxygen saturation $(\%)$ & $77 \pm 0$ & $72 \pm 3$ & .0122 \\
\hline Postoperative oxygen saturation at discharge $(\%)$ & $83 \pm 0$ & $82 \pm 1$ & .4764 \\
\hline Left pulmonary size $(\mathrm{cm})$ & $0.51 \pm 0.04$ & $0.42 \pm 0.03$ & .4311 \\
\hline Right pulmonary size $(\mathrm{cm})$ & $0.52 \pm 0.03$ & $0.47 \pm 0.03$ & .5643 \\
\hline \multirow[t]{3}{*}{ Atrioventricular valve regurgitation } & Absent: $49 \%$ & Absent: $60.0 \%$ & .4929 \\
\hline & Mild: $40.9 \%$ & Mild: $30.0 \%$ & .4987 \\
\hline & Moderate: $10.1 \%$ & Moderate: $10.0 \%$ & .7029 \\
\hline \multirow[t]{2}{*}{ Antegrade flow before BDG procedure } & Yes: $57(33.7 \%)$ & Yes: $1470.0 \%$ & 0.0127 \\
\hline & No: $112(66.3 \%)$ & No: $6(30.0 \%)$ & \\
\hline \multirow[t]{2}{*}{ Antegrade flow after BDG procedure } & Yes: $17(10.06 \%)$ & Yes: $5(25.0 \%)$ & 1891 \\
\hline & No: $152(90.0 \%)$ & No: $15(75.0 \%)$ & \\
\hline Presence of left superior vena cava & Yes: $10.1 \%(15)$ & Yes: $0.0 \%(0)$ & .0633 \\
\hline
\end{tabular}

$Q p: Q s$, Indexed pulmonary and systemic cardiac output ratio; $B D G$, bidirectional Glenn.

those of patients with non-HLHS $(81 \% \pm 5 \%$ vs $83 \% \pm$ $5 \%, P=.001)$.

\section{DISCUSSION}

A number of prior reports have documented the feasibility of performing an early BDG procedure. ${ }^{3-6,10,11}$ Table $5^{2,3,4,10-12}$ summarizes data from prior reports and the current study. Performance of the BDG procedure, currently typically done before 6 months of age, ${ }^{2,3}$ was historically reported to be associated with poorer outcomes in younger patients. ${ }^{6}$ Others had argued against performing the BDG procedure in patients 2 months of age or younger. ${ }^{3}$

In our series we showed low mortality among patients less than 3 months of age, with approximately $35 \%$ of the younger cohort being only 2 months old. Our results are similar to other recent reports of excellent outcomes after the BDG procedure, ${ }^{4}$ which is perhaps a reflection of an era effect. Our only death in the less than 3-month-old cohort was a patient with HLHS who underwent the Norwood procedure on day 3 of life. This patient underwent mechanical ventilation for his entire life, never left the hospital, and underwent the BDG procedure with multiple comorbidities. Not surpris-

TABLE 4. Late outcomes after the BDG procedure (excluding operative mortality)

\begin{tabular}{lccr}
\hline & $\begin{array}{c}\text { Older group } \\
(\mathbf{n}=\mathbf{1 4 7})\end{array}$ & $\begin{array}{c}\text { Younger group } \\
(\mathbf{n}=\mathbf{1 9})\end{array}$ & $\boldsymbol{P}$ value \\
\hline Died & $6(4.1 \%)$ & $0(0.0 \%)$ & .8046 \\
Not candidate & $5(3.4 \%)$ & $0(0.0 \%)$ & .8995 \\
$\quad$ for Fontan procedure & & & \\
Waiting for Fontan procedure & $43(29.3 \%)$ & $9(47.4 \%)$ & .1046 \\
Transplantation & $4(2.7 \%)$ & $0(0.0 \%)$ & .9702 \\
Fontan procedure & $89(60.5 \%)$ & $10(52.6 \%)$ & .5685 \\
\hline
\end{tabular}

ingly, this patient had a protracted ICU stay, ventilation time, and hospital stay as well.

Intuitively, one might expect that the HLHS subset of patients would be perhaps at higher risk for poor outcomes. When analyzing the subgroup of patients with HLHS versus those with other diagnoses, however, we found similar outcomes; again, age was not predictive of mortality risk. Furthermore, both groups, younger and older than 3 months, were comparable in terms of hemodynamic data, as well as echocardiographic measurements. The main differences between our groups were weight, body surface area, age, hospital length of stay, ICU length of stay, mechanical ventilation duration, time from admittance to the BDG procedure, and number of prior operations. Weight, body surface area, and age were not surprising considering the group definitions. The younger group had a less smooth postoperative course, as evidenced by longer hospital length of stay, ICU length of stay, and mechanical ventilation duration, but this did not result in increased early or late mortality, which is consistent with prior reports. ${ }^{13,14}$ We make a concerted effort to wean patients off any supplemental oxygen before hospital discharge, which could have resulted in longer hospital length of stay for the younger group. Whether the increased ICU (median of 4 vs 3 days for the younger vs older groups) or ventilation time is of clinical significance is questionable. In addition, the increased ventilation time and ICU and hospital length of stay and associated costs have to be contrasted versus the substantially fewer prior operations the younger group had relative to the older group (ie, skipping 1 prior palliative procedure). In the younger group 10 patients had prior operations. In this subgroup 7 had first-stage palliation for HLHS, and only 1 remained in the hospital until the BDG procedure. The remaining 10 younger patients underwent semielective 


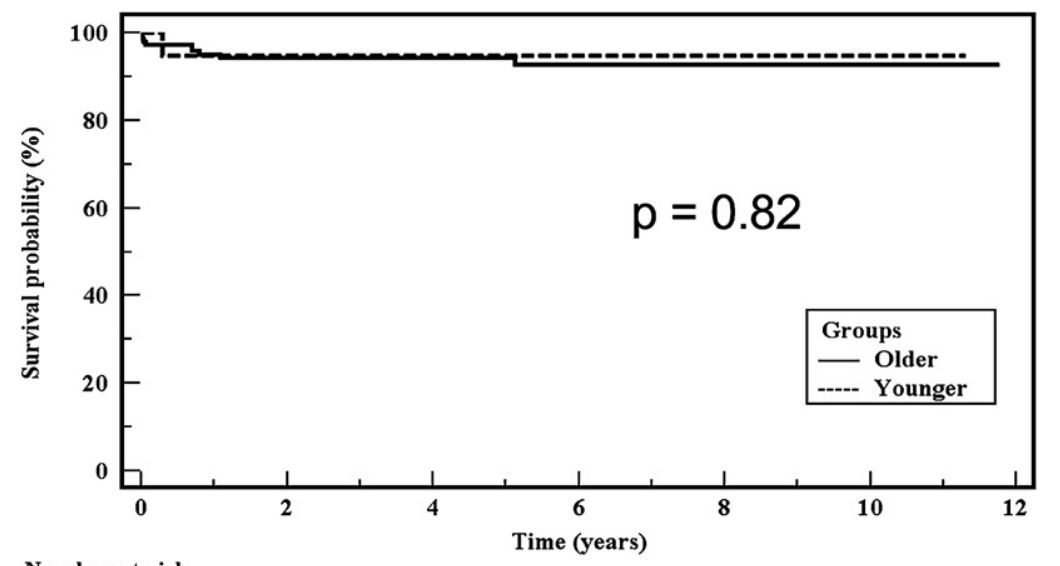

Number at risk

\begin{tabular}{|c|c|c|c|c|c|c|}
\hline Group: Older & & & & & & \\
\hline 149 & 108 & 74 & 49 & 24 & 12 & 1 \\
\hline Group: Younger & & & & & & \\
\hline 20 & 12 & 9 & 3 & 1 & 1 & 0 \\
\hline
\end{tabular}

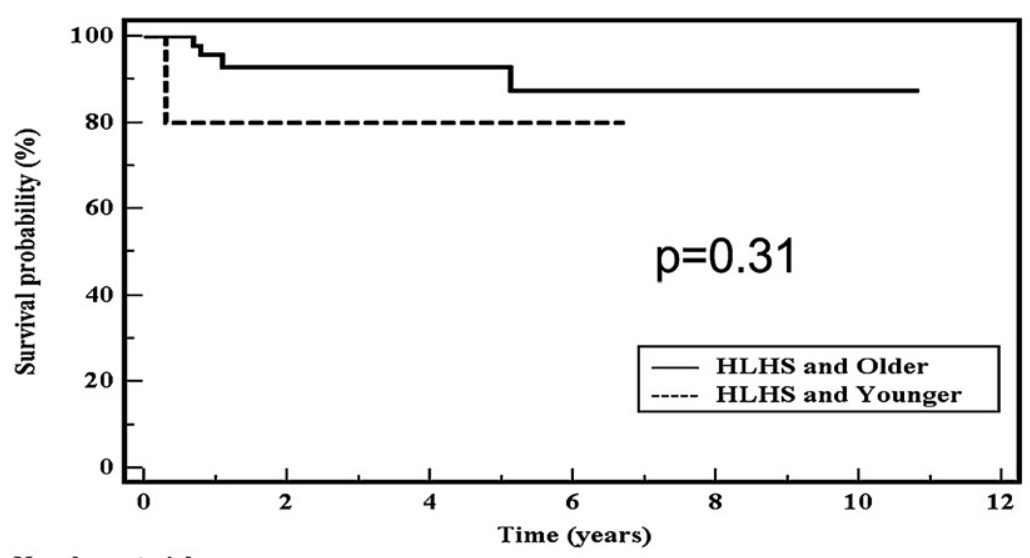

Number at risk

\begin{tabular}{|c|c|c|c|c|c|c|}
\hline 49 & 32 & 24 & 14 & 6 & 3 & 1 \\
\hline Group: Younger & & & & & & \\
\hline B 5 & 3 & 3 & $\mathbf{1}$ & $\mathbf{0}$ & 0 & 0 \\
\hline
\end{tabular}

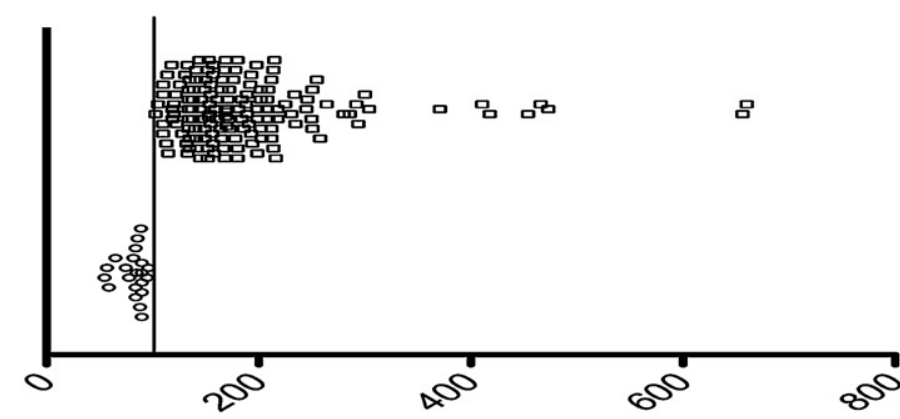

C

Age at Glenn (days)

FIGURE 1. A, actuarial curve for death after the bidirectional Glenn $(B D G)$ procedure in the younger and older groups. B, actuarial curve for death for patients with hypoplastic left heart syndrome $(H L H S)$ in the younger and older groups. C, Scatter plot of age distribution of patients at the time of the BDG procedure. The $x$-axis is age at the time of the BDG procedure in days. A line demarcates the separation of the older and younger group at 3 months of age. 
TABLE 5. Summarized data from prior reports and the current study

\begin{tabular}{lcccc}
\hline \multicolumn{1}{c}{ Author } & Year & $\begin{array}{c}\text { No. of } \\
\text { patients }\end{array}$ & $\begin{array}{c}\text { Average age } \\
\text { at BDG } \\
\text { procedure } \\
\text { (mo) }\end{array}$ & $\begin{array}{c}\text { Hospital } \\
\text { mortality } \\
\text { (30 d) }\end{array}$ \\
\hline Present report $^{\text {Jaquiss and coworkers }}{ }^{4}$ & 2008 & 20 & 2.8 & $5.0 \%$ \\
Bradley and coworkers $^{11}$ & 2004 & 33 & 3.1 & $0.0 \%$ \\
Slavik and coworkers $^{10}$ & 1996 & 85 & 4.8 & $5.9 \%$ \\
Reddy and coworkers $^{3}$ & 1996 & 4 & 1.3 & $0.0 \%$ \\
Reddy and coworkers $^{2}$ & 1997 & 42 & 3.7 & $4.8 \%$ \\
Chang and coworkers $^{12}$ & 1995 & 9 & 2.6 & $0.0 \%$ \\
\hline
\end{tabular}

procedures in which the BDG procedure was done in lieu of a BT shunt.

We observed that the younger group had longer hospital admittance periods before the BDG procedure, which is likely reflective of the surprise presentation of these children with either newly discovered congenital heart disease and cyanosis or sudden deterioration of the clinical status after prior palliative procedures.

Previous reports had suggested that performance of a BDG procedure in patients less than 6 months of age would result in lower oxygen saturations. ${ }^{10,11}$ A more recent report by Jaquiss and colleagues ${ }^{4}$ also showed that patients who underwent the BDG procedure at an age of less than 4 months had lower postoperative saturations and longer ICU and hospital stays. In the preceding study all patients had undergone the Norwood procedure, and more than $60 \%$ had a primary diagnosis of HLHS. ${ }^{4}$ Overall, however, the oxygen saturation difference between the groups was small $(75 \%$ vs $81 \%)$ and showed minimal clinical significance. In contrast, we found that the post-BDG oxygen saturations at hospital discharge were comparable between the groups, and certainly none of the younger patients was discharged on supplemental oxygen. Our study, however, includes not only patients with HLHS, as in Jaquiss and colleagues' study, ${ }^{4}$ but also patients with other single-ventricle anatomy. Consistent with Jaquiss and colleagues' report, we also showed that patients with HLHS overall also had lower oxygen saturations when compared with other patients with single-ventricle physiology. Therefore it appears that the primary diagnosis might have greater influence on postoperative saturations than age at the time of the BDG procedure.

The presence of antegrade pulmonary blood flow after the BDG procedure has been a controversial subject. ${ }^{15}$ Antegrade flow has been demonstrated both to improve and complicate the immediate postoperative and interstage clinical course after the BDG procedure. ${ }^{16,17}$ Advantages of antegrade native pulmonary flow include promotion of normal pulmonary artery growth and maintenance of pulmonary artery endothelial function. ${ }^{16,18} \mathrm{We}$ showed an improvement in postoperative oxygen saturation after the BDG procedure in patients who previously had antegrade flow (ie, before the BDG procedure). The presence of antegrade flow before the BDG procedure was not associated with death or poor outcome after the BDG procedure in our series. Because we had only 22 patients with antegrade pulmonary blood flow after the BDG procedure (17 in the older group and 5 in the younger group), we did not find any influence of antegrade flow after the BDG procedure on stepwise regression analysis. Calvaruso and associates, ${ }^{19}$ in a recent article, showed improvement in survival and oxygen saturations, with maintenance of antegrade flow after the BDG procedure. Kogon and coworkers ${ }^{11}$ recently also showed that outcomes were unaffected by the presence of antegrade pulmonary blood flow after the BDG procedure, complementing our findings. Therefore antegrade pulmonary blood flow does not preclude progression and completion of the Fontan procedure and might indeed be a positive influence, particularly in terms of reducing the risk of arteriovenous malformations.

It is difficult to say how early the BDG procedure can be safely performed, but based on our study results, we believe that performing the $\mathrm{BDG}$ procedure at 2 months of age is feasible and safe. Ghanayem and colleagues, ${ }^{9}$ with a home-based monitoring system after the Norwood procedure, showed an overall improvement in survival rates associated with shortening of time to second-stage palliation. The patients with home-based monitoring systems proceeded to the second stage at a mean age of 4.2 months compared with patients not monitored at home, who proceeded to the second stage at a mean age of 5.6 months. Indeed, one of the strongest benefits of an early BDG procedure is the potential decrease in interstage attrition, which was reported by Ghanayem and colleagues in the range of $10 \%$ to $15 \%$.

Because age did not appear to affect mortality in our study, we carried out further analysis of variables that might affect outcomes after the BDG procedure for the overall population of patients. This analysis led to identification of 3 variables as having an influence on mortality after the BDG procedure consistent with prior reports $^{2,13,18,20}$ : mean pulmonary artery pressure, AV valve regurgitation, and postoperative oxygen saturations at discharge. Bridges and associates ${ }^{21}$ have shown that older patients are prone to higher pulmonary artery pressures and are more cyanotic after the BDG procedure, which is supportive of the importance of not delaying the BDG procedure for too long. As in prior reports, ${ }^{3,13,21}$ the adverse effects of AV regurgitation in our study are likely reflective of decreased effective cardiac output and increased cardiac workload. A number of factors might contribute to the regurgitation, including prolonged volume overload from systemic to pulmonary shunts. This situation causes an increase in myocardial mass and ventricular cavity enlargement. ${ }^{22}$ Observation of structural myocyte changes in 
experimental models of volume overload ${ }^{23}$ and changes in cardiac collagen and elastin observed in experimental models related to arteriovenous shunts ${ }^{24}$ again argue that early intervention toward a more efficient flow circuit (ie, the BDG procedure) would be beneficial.

Our study has several limitations, including all limitations related to a retrospective study from a single institution. Furthermore, the small number of patients in the younger group limits the statistical power of the study. Finally, having performed a retrospective study, we cannot adequately answer the question of why the patients in the younger group had their BDG procedures early. As in any procedure, the indication for that procedure can have a significant effect on outcomes. We suspect that earlier in our study the indication for an early BDG procedure was mainly related to lower oxygen saturations in patients with likely less than optimal hemodynamics. More recently, we have been more aggressive about "elective" implementation of the BDG procedure in patients once they reach the age of 2 months. Whether the results will be different in the upcoming era because of this change in philosophy has yet to be determined, but we suspect that such an approach will result in data that are even more favorable. Lastly, we did not evaluate whether cerebral perfusion in these very young patients was affected. More refined studies are necessary in the future to address this question.

In conclusion, carrying out the BDG procedure in patients less than 3 months of age (as early as 2 months) is safe, with favorable long-term results. The early conversion of the pulmonary blood flow source from a systemic to pulmonary artery shunt to a cavopulmonary anastomosis has advantages when done as soon as possible. $\mathrm{Li}$ and associates $^{25}$ have shown that after Norwood palliation, the required indexed cardiac output is on the order of $4 \mathrm{~L} /$ min. The same analysis after the BDG procedure revealed a value closer to $3 \mathrm{~L} / \mathrm{min} .{ }^{26}$ Clearly, the BDG procedure is a more efficient circulation than systemic to pulmonary artery shunting. It is for the preceding and other reasons noted before that we believed that performance of the BDG procedure as early as possible could lead to better long-term outcomes. ${ }^{20}$

\section{References}

1. Lamberti JJ, Spicer RL, Waldman JD, Grehl TM, Thomson D, George L, et al. The bidirectional cavopulmonary shunt. J Thorac Cardiovasc Surg. 1990;100: 22-30.

2. Reddy VM, Liddicoat JR, Hanley FL. Primary bidirectional superior cavopulmonary shunt in infants between 1 and 4 months of age. Ann Thorac Surg. 1995;59: 1120-1126.

3. Reddy VM, McElhinney DB, Moore P, Haas GS, Hanley FL. Outcomes after bidirectional cavopulmonary shunt in infants less than 6 months old. J Am Coll Cardiol. 1997;29:1365-1370.

4. Jaquiss RD, Ghanayem NS, Hoffman GM, Fedderly RT, Cava JR, Mussatto KA, et al. Early cavopulmonary anastomosis in very young infants after the Norwood procedure: impact on oxygenation, resource utilization, and mortality. $J$ Thorac Cardiovasc Surg. 2004;127:982-989.
5. Ashburn DA, Blackstone EH, Wells WJ, Jonas RA, Pigula FA, Manning PB, et al. Determinants of mortality and type of repair in neonates with pulmonary atresia and intact ventricular septum. J Thorac Cardiovasc Surg. 2004;127:1000-1008.

6. Kopf GS, Laks H, Stansel HC, Hellenbrand WE, Kleinman CS, Talner NS. Thirty-year follow-up of superior vena cava-pulmonary artery (Glenn) shunts. $J$ Thorac Cardiovasc Surg. 1990;100:662-671.

7. di Carlo D, Williams WG, Freedom RM, Trusler GA, Rowe RD. The role of cavapulmonary (Glenn) anastomosis in the palliative treatment of congenital heart disease. J Thorac Cardiovasc Surg. 1982;83:437-442.

8. Tanoue Y, Sese A, Ueno Y, Joh K, Hijii T. Bidirectional Glenn procedure improves the mechanical efficiency of a total cavopulmonary connection in highrisk Fontan candidates. Circulation. 2001;103:2176-2180.

9. Ghanayem NS, Tweddell JS, Hoffman GM, Mussatto K, Jaquiss RD. Optimal timing of the second stage of palliation for hypoplastic left heart syndrome facilitated through home monitoring, and the results of early cavopulmonary anastomosis. Cardiol Young. 2006;16(suppl 1):61-66.

10. Slavik Z, Lamb RK, Webber SA, Devlin AM, Keeton BR, Monro JL, et al. Bidirectional superior cavopulmonary anastomosis: how young is too young? Heart. 1996;75:78-82.

11. Bradley SM, Mosca RS, Hennein HA, Crowley DC, Kulik TJ, Bove EL. Bidirectional superior cavopulmonary connection in young infants. Circulation. 1996;(suppl):94:II5-11.

12. Chang AC, Hanley FL, Wernovsky G, Rosenfeld HM, Wessel DL, Jonas RA, et al. Early bidirectional cavopulmonary shunt in young infants. Postoperative course and early results. Circulation. 1993;88(5 Pt 2):II149-58.

13. Jaquiss RD, Tweddell JS. The neonate with congenital heart disease: what the cardiac surgeon needs to know from the neonatologist and the cardiologist. Clin Perinatol. 2005;32:947-961, ix.

14. Kogon BE, Plattner C, Leong T, Simsic J, Kirshbom PM, Kanter KR. The bidirectional Glenn operation: a risk factor analysis for morbidity and mortality. J Thorac Cardiovasc Surg. 2008;136:1237-1242.

15. McElhinney DB, Marianeschi SM, Reddy VM. Additional pulmonary blood flow with the bidirectional Glenn anastomosis: does it make a difference? Ann Thorac Surg. 1998;66:668-672.

16. Caspi J, Pettitt TW, Ferguson TB Jr, Stopa AR, Sandhu SK. Effects of controlled antegrade pulmonary blood flow on cardiac function after bidirectional cavopulmonary anastomosis. Ann Thorac Surg. 2003;76:1917-1922.

17. Aeba R, Katogi T, Kashima I, Omoto T, Kawada S, Omae K. Factors influencing arterial oxygenation early after bidirectional cavopulmonary shunt without additional sources of pulmonary blood flow. J Thorac Cardiovasc Surg. 2000;120: 589-595.

18. Caspi J, Pettitt TW, Mulder T, Stopa A. Development of the pulmonary arteries after the Norwood procedure: comparison between Blalock-Taussig shunt and right ventricular-pulmonary artery conduit. Ann Thorac Surg. 2008;86:1299-1304.

19. Calvaruso DF, Rubino A, Ocello S, Salviato N, Guardi D, Petruccelli DF, et al. Bidirectional Glenn and antegrade pulmonary blood flow: temporary or definitive palliation? Ann Thorac Surg. 2008;85:1389-1396.

20. Jaquiss RD, Siehr SL, Ghanayem NS, Hoffman GM, Fedderly RT, Cava JR, et al. Early cavopulmonary anastomosis after Norwood procedure results in excellent Fontan outcome. Ann Thorac Surg. 2006;82:1260-1266.

21. Bridges ND, Jonas RA, Mayer JE, Flanagan MF, Keane JF, Castaneda AR. Bidirectional cavopulmonary anastomosis as interim palliation for high-risk Fontan candidates. Early results. Circulation. 1990;(suppl):82:IV170-6.

22. Jacobs ML, Rychik J, Rome JJ, Apostolopoulou S, Pizarro C, Murphy JD, et al. Early reduction of the volume work of the single ventricle: the hemi-Fontan operation. Ann Thorac Surg. 1996;62:456-462.

23. Spinale FG, Ishihra K, Zile M, DeFryte G, Crawford FA, Carabello BA. Structural basis for changes in left ventricular function and geometry because of chronic mitral regurgitation and after correction of volume overload. J Thorac Cardiovasc Surg. 1993;106:1147-1157.

24. Ruzicka M, Keeley FW, Leenen FH. The renin-angiotensin system and volume overload-induced changes in cardiac collagen and elastin. Circulation. 1994;90: 1989-1996.

25. Li J, Zhang G, Holtby H, Guerguerian AM, Cai S, Humpl T, et al. The influence of systemic hemodynamics and oxygen transport on cerebral oxygen saturation in neonates after the Norwood procedure. J Thorac Cardiovasc Surg. 2008;135: 83-90, e1-2.

26. Hoskote A, Li J, Hickey C, Erickson S, Van Arsdell G, Stephens D, et al. The effects of carbon dioxide on oxygenation and systemic, cerebral, and pulmonary vascular hemodynamics after the bidirectional superior cavopulmonary anastomosis. J Am Coll Cardiol. 2004;44:1501-1509. 